\title{
Hydraulic Fracturing and Underground Coal Gasification in Connection with Hydrolytic Disproportionation of Carbon
}

\author{
Vladimir Vigdergauz* \\ Russian Academy of Sciences, Russia

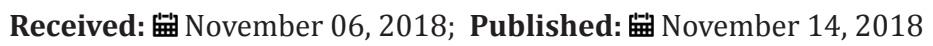 \\ *Corresponding author: Vladimir Vigdergauz, Russian Academy of Sciences, Russia
}

\section{Opinion}

Hydrolytic disproportionation of carbon (HDC) was proposed as an essential reaction in connection with coal mine methane formation in catastrophic events [1,2]. The calculated Gibbs free energy change of HDC or direct reduction of hydrogen from its oxide by coal in the form of carbon is $29.20 \mathrm{~kJ} / \mathrm{mol}$ of methane or $14.60 \mathrm{~kJ} / \mathrm{mol}$ of carbon. It was shown that reaction of methane formation from carbon and water is a slightly endothermic process, but the products entropy increases, and the reaction is productfavored. Reaction entropy positive and this reaction could be an "entropy driven". There was proposed a possibility that the size and tetrahedral structure of methane molecules, similar to the stereochemistry of the holes of water clathrates, gives additional features of favorable stereochemistry during the formation of intermediate stereo-structures of hydrotated coal rings, acetic acid like dimers and polymers and their subsequent transformation and decomposition during HDC with the production of methane and carbon dioxide as the final substances.

During catastrophic events reaction energy could be compensated by the exothermic reaction of partial oxidation of methane. Evaluation of the critical conditions of HDC shows that under the normal pressure Gibbs free energy becomes equal to zero under the temperatures of about $142^{\circ} \mathrm{C}$. This temperature might be considered as a critical for methane and carbon dioxide irreversible formation under the normal pressure.

Usually temperatures near $140^{\circ} \mathrm{C}$ are characteristic for the depths near $4 \mathrm{~km}$ [3], but various mining and geological peculiarities could drastically change the situation. Methane formation might be stimulated artificially, and it is done in the technologies of underground coal gasification (UCG) and hydraulic fracking (HF).
The most successful industrial exploitation of coalbed methane occurs primarily in coals of the Fruitland Formation [4,5]. About 2,550 wells were operating in the San Juan Basin in 2001. All wells are vertical wells that range from about 500 to 4,000 feet in depth and were drilled using water or water-based muds. Almost every well has been fracture-stimulated, using either conventional hydraulic fracturing in perforated casing or cavitation cycling in open holes. Each fracture stimulation treatment may inject, on average, approximately 55,000 to 300,000 gallons of stimulation and fracturing fluid per treatment. Total gas production was 925 Bcf in 2000 [1]. Modern technologies of natural gas producing including HF and UCG processes have a great impact to the Earth ecology and HDC reaction might be crucial for our understanding of the possibilities to regulate them.

\section{References}

1. Vigdergauz VE (2011) Methane Formation by the Reaction of Coalbed Carbon with Water. Geomaterials 1(1): 21-23.

2. Vigdergauz VE (2014) Evidence for and Thermodynamics of Coal Mine Methane Formation in Catastrophic Events by the Hydrolytic Disproportionation of Carbon. International Union of Geological Sciences 37(1): 14-20.

3. Helgeson HC, Richard L, McKenzie WF, Norton DL, Schmitt A (2009) A chemical and thermodynamic model of oil generation in hydrocarbon source rocks. Geochimica et Cosmochimica Acta 73(3): 594-695.

4. 2002 Drilling and Production Statistics for Major US Coalbed Methane and Gas Shale Reservoirs. Gas Technology Institute (GTI).

5. Pashin JC, McIntyre MR (2003) Temperature-pressure conditions in coalbed methane reservoirs of the Black Warrior basin: implications for carbon sequestration and enhanced coalbed methane recovery. International Journal of Coal Geology 54(3-4): 167-183. 


\section{(C) (P) This work is licensed under Creative}

To Submit Your Article Click Here: Submit Article

DOI: $10.32474 /$ MAOPS.2018.02.000137

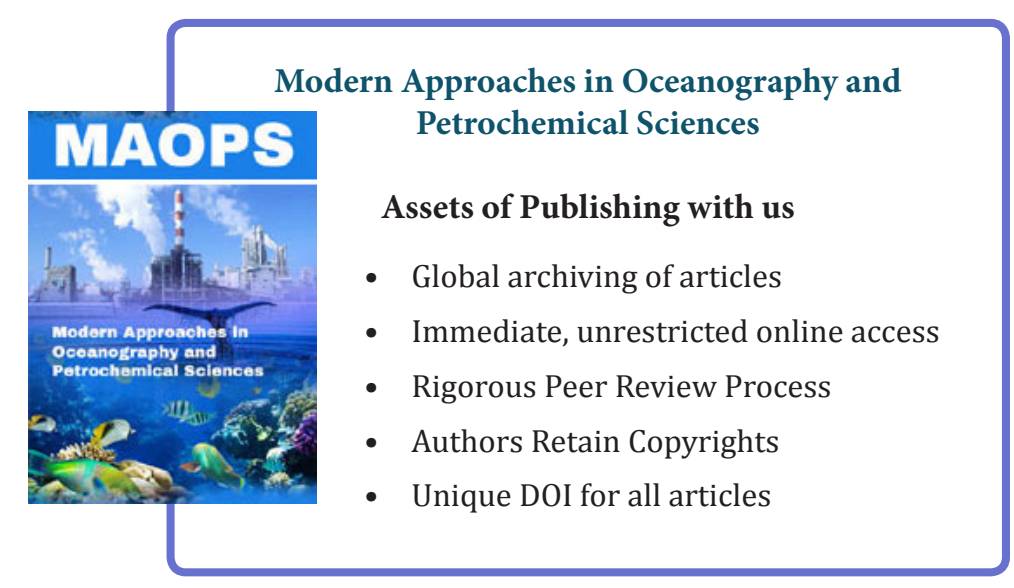

